\title{
Molecular Mechanisms of Anti-metastatic Activity of Curcumin
}

\author{
YI DENG ${ }^{1}$, ELISE VERRON ${ }^{2}$ and RAMIN ROHANIZADEH ${ }^{1}$ \\ ${ }^{1}$ University of Sydney, Faculty of Pharmacy, Sydney, Australia; \\ ${ }^{2}$ Université de Nantes, UFR des Sciences Pharmaceutiques et Biologiques, Nantes, France
}

\begin{abstract}
Cancer is the leading cause of death worldwide. Although cancer occurs as a localized disease, its morbidity and mortality rates remain high due to the ability of cancer cells to break-off from the primary tumor and spread to distant organs. Currently, chemotherapy is the main treatment for cancer; however, the increase in proportion of drug-resistant cancer cells and unpleasant side-effects of chemotherapy are still the major challenges in cancer therapy. Curcumin is a natural polyphenol compound and the main bioactive constituent of Indian spice turmeric, widely used in Indian and Chinese medicines. Curcumin has well-known therapeutic actions, including antiinflammatory, anti-microbial, anti-oxidant and anti-cancer properties. Curcumin induces cancer cell apoptosis through regulating various signaling pathways and arresting tumor cell cycle. Curcumin's therapeutic/ preventative actions on metastatic cancers have not been yet fully understood and studied. The present review explores the potential anti-metastatic mechanisms of curcumin, including inhibition of transcription factors and their signaling pathways (e.g., NF-kB, ApP-1 and STAT3), inflammatory cytokines (e.g., CXCL1, CXCL2, IL-6, IL-8), multiple proteases (e.g., uPA, MMPs), multiple protein kinases (e.g., MAPKs, FAK), regulation of miRNAs (e.g., miR21, miR181b) and heat shock proteins (HLJ1). In addition, possible synergistic actions of combination therapy of curcumin with current chemotherapies are discussed in this review.
\end{abstract}

Despite all recent advances in oncology, cancer is still one of the deadliest diseases around the world (1). Cancer occurs as

This article is freely accessible online.

Correspondence to: Dr. Ramin Rohanizadeh, Pharmacy Building (A15), University of Sydney, Faculty of Pharmacy, Sydney, New South Wales 2006, Australia. Tel: +61 293512355, Fax: +61 293514391 e-mail: ramin.rohanizadeh@sydney.edu.au

Key Words: Curcumin, cancer treatment and prevention, metastasis, cancer invasion, signaling pathways, review. a localized disease but can spread to distant organs through migration, invasion and metastasis (2). Metastatic cancer is one of the major causes of death in cancer patients. Metastasis is a complex process involving multiple steps: (i) local migration through degrading basement membrane and extracellular matrix (ECM), (ii) intravasation into blood and/or lymphatic vessels, (iii) circulating to the target organ site, (iv) extravasation into target organ tissue and, finally, (v) multiplication in the target organ $(2,3)$. These steps are mediated by various factors, including growth factors, proteolysis degradation of extracellular matrix, cell-cell adhesion, cytoskeleton remodeling and changes of genes' expressions $(2,3)$. Metastasis is a non-random process that means each metastatic cancer type has its own preferred site of metastasis. For example, breast cancer cells preferentially metastasize to regional lymph nodes, liver, lungs and bone (4). Nowadays, there are different therapeutic approaches available for patients with metastatic cancers, including surgery, radiotherapy and chemotherapy. Chemotherapy remains the main treatment modality for cancer patients because of its ability of preventing invasion and metastasis. However, the morbidity and mortality rates in patients with metastatic cancer still remain high since current chemotherapy agents fail to selectively and effectively kill cancer cells without destroying normal cells at the sites of metastasis (5). Therefore, finding a safe and effective preventative approach to inhibit invasion of cancer cells from primary tumor and, thereby, prevent metastatic process in the first place is a critical step to cure the disease or increase life expectancy of cancer patients.

Curcumin (diferuloylmethane), the main biologically active compound of Indian spice turmeric, is a polyphenol compound (Figure 1) derived from the roots of Curcuma longa. Turmeric commonly used as a dietary spice and coloring agent in different countries and has been widely used as a therapeutic and preventive agent for various illnesses and medical conditions. Curcumin has well-known biological activities that include anti-inflammatory, antioxidant, anti-microbial, wound healing and anti-cancer properties (6-10). Studies have shown that curcumin is able 
<smiles>COc1ccc(/C=C/C(=O)CC(=O)/C=C/c2ccc(OC)c(O)c2)cc1O</smiles>

Figure 1. Chemical structure of curcumin.

to interfere with tumor cell cycle, thereby suppressing the growth of cancer cells and preventing invasion and metastasis $(8,10-13)$. Curcumin also has the ability to inhibit invasion and metastasis of cancer cells through regulating the expression of inflammatory cytokines, growth factors, growth factors' receptors, enzymes, adhesion molecules, apoptosis-related proteins and cell cycle proteins (10, 13-16). Curcumin modulates the activity of oncogenes, tumor suppressor genes, several transcription factors and their signaling pathways $(10,13,15,17)$.

In recent years, anti-cancer properties of curcumin have attracted attention in medicine. There exist many studies that have shown curcumin is able to suppress the growth of cancer cells by various molecular mechanisms, but mainly through apoptosis. As metastasis is one of the major factors contributing to poor cancer survival rate, there are many studies that looked into the anti-invasive and anti-metastatic effects of curcumin in various cancers. This review will look into the effects of curcumin on different signaling pathways and explore the possible underlying anti-invasion and antimetastasis mechanisms of curcumin on cancer cells. Table I summarizes various molecular mechanisms and signaling pathways through which curcumin inhibits cancer cell migration, invasion and metastasis.

\section{Potential Anti-migration, Anti-invasion and Anti-colony Formation Mechanisms of Curcumin on Cancer Cells}

Curcumin inhibits nuclear factor-kappa $B(N F-k B)$ activation. $\mathrm{NF}-\mathrm{kB}$ is the one of the primary transcription factors to regulate genes that control cell proliferation and survival (18). Although the activation of $\mathrm{NF}-\mathrm{kB}$ signaling pathway is important for immune system to fight against infections, the constitutive activation of NF-kB (Figure 2) will mediate carcinogenesis by suppressing apoptosis and leading to progression of cancers. NF-kB-regulated gene products that control tumor invasion include matrix metalloprotinases (MMP), urokinase-type plasminogen activator (uPA), interlukin-8 (IL-8) and other chemokines $(18,19)$. Once NF$\mathrm{KB}$ is activated, for example by bacterial or viral infections, it activates IkB kinase (IKK) enzymes, that are responsible to phosphorylate and degrade $\operatorname{IkB} \alpha$ (inhibitor of $\mathrm{kB}$, alpha).
$\mathrm{IkB} \alpha$ is one of the inhibitors of $\mathrm{kB}(\mathrm{IkB})$ protein family, which inhibits the NF-kB activation by keeping them sequestered in an inactive state in the cytoplasm and by blocking their ability to bind to DNA $(20,21)$. Increasing IKK activation, promotes phosphorylation and, thereby, degradation of $\operatorname{IkB} \alpha$, leading to a constitutive activation of NF-kB. However, NF-kB activation also turns on the expression of genes that result in synthesizing of new IkB $\alpha$, which then re-inhibits NF-kB and forms an auto-feedback loop to stop further NF-kB activation (22). Therefore, the inhibition of NF- $\mathrm{KB}$ transcription factor is one of the main targets for preventing cancer progression. Studies have also reported that NF-kB activation is one of the mechanism for chemotherapy resistance in cancer cells (23) and that the inhibition of NF-KB pathway can increase the efficacy of cancer therapy.

Cancer tumor promoter molecules, such as phorbol ester (12-O-tetradecanoylphorbol-13-acetate is the most common one), tumor necrosis factor (TNF) and hydrogen peroxide induce the activation of $\mathrm{NF}-\mathrm{kB}(17,24)$ and several works have shown curcumin can inhibit this activation. Bachmeier et al. (25) and Killian et al. (26) reported that curcumin prevents NF-kB activation by inhibiting phosphorylation and degradation of $\operatorname{IkB} \alpha$. Curcumin is also shown to inhibit the activation of p65 (one of the NF-kB transcription factor family) in estrogen receptor (ER)-negative breast cancer cells (25) and in prostate cancer cells (26). Singh et al. showed that curcumin inhibits NF-kB activation pathway in the signal transduction cascade of NF-kB activation before the IkB $\alpha$ phosphorylation but after the point at which signals transduced by various stimuli converge (27). Zong et al. showed that curcumin is an inhibitor of NF-kB in a dosedependent manner in a breast cancer cell line (11). Inhibiting or down-regulating NF-kB activation by curcumin leads to down-regulation of the expression of various proliferative genes and induction of apoptosis, therefore, preventing tumor cells' invasion and metastasis (Figure 3).

Curcumin inhibits activator protein $1(A P-1)$ activation. AP1 is another important transcription factor that regulates the expression of different genes affecting cellular processes, such as proliferation and apoptosis. Activation of AP-1 complex in different cancer cells is regulated, at least in part, by activation of stress-activated kinase C-Jun N-terminal kinase (JNK) that stimulates the transactivating potency of AP-1 activation, thereby increasing the expression of AP-1 target genes $(24,28)$. It has been shown that curcumin inhibits the activation of AP-1 by interacting with the AP-1 DNA-binding motif and inhibits JNK activation (24). Curcumin inhibits the activation of AP-1 in colorectal (29) and breast cancer cells (14). Wang et al. reported that neurotensin increased AP-1 DNA-binding activity and curcumin inhibited the neurotensin-mediated AP-1 activation in a colon cancer cell line (30). 
Table I. Summary of potential underlying molecular mechanisms of curcumin to inhibit cancer migration, invasion and metastasis.

\begin{tabular}{|c|c|c|c|}
\hline Mechanism of actions & In vitro/In vivo & Outcomes/effects & Ref. \\
\hline $\begin{array}{l}\text { Nuclear factor-kappa B } \\
(\mathrm{NF}-\mathrm{kB}) \text { activation }\end{array}$ & In vitro & $\begin{array}{c}\text { Curcumin inhibits NF-kB activation in } \\
\text { a dose-dependent manner }\end{array}$ & $(11,17,24-26)$ \\
\hline Activator protein $1(\mathrm{AP}-1)$ activation & In vitro & Curcumin inhibits AP-1 activation & $(14,30)$ \\
\hline Signal transducer and activator of transcription 3 (STAT3) & In vitro & Curcumin inhibits STAT3 phosphorylation & $(16,24)$ \\
\hline Inflammatory cytokines' expression & $\begin{array}{l}\text { In vitro } \\
\text { In vivo (mice) }\end{array}$ & $\begin{array}{l}\text { Curcumin suppresses CXCL-1,-2 } \\
\text { expression and protein secretion }\end{array}$ & $(25,26)$ \\
\hline Interleukin expression & In vitro & $\begin{array}{l}\text { Curcumin inhibits neurotensin-induced } I L-8 \\
\text { gene expression and protein secretion } \\
\text { in a dose-dependent manner }\end{array}$ & $(30)$ \\
\hline Urokinase plasminogen activator (uPA) expression & In vitro & $\begin{array}{l}\text { Curcumin suppresses uPA expression } \\
\text { in a dose-dependent manner }\end{array}$ & $(11)$ \\
\hline $\begin{array}{l}\text { Matrix metalloproteinases (MMPs) and tissue } \\
\text { inhibitors of metalloproteinases' (TIMPs) expression }\end{array}$ & $\begin{array}{l}\text { In vitro } \\
\text { In vivo (mice) }\end{array}$ & $\begin{array}{l}\text { Curcumin suppresses MMP- } 2,-9 \text { expression } \\
\text { and enhances TIMP- } 1,-2,-4 \text { expressions }\end{array}$ & $\begin{array}{l}(12-14,42, \\
44-47)\end{array}$ \\
\hline Focal adhesion kinase (FAK) activity & $\begin{array}{l}\text { In vitro } \\
\text { In vivo (mice) }\end{array}$ & Curcumin suppresses FAK activity & $(49,50)$ \\
\hline MicroRNAs (miRNAs) expression & $\begin{array}{l}\text { In vitro } \\
\text { In vivo (chicken and mice) }\end{array}$ & $\begin{array}{l}\text { Curcumin suppresses miR21 expression } \\
\text { and enhances miR181b expression }\end{array}$ & $(51,53)$ \\
\hline DnaJ-like heat shock protein 40 (HLJ1) expression & $\begin{array}{l}\text { In vitro } \\
\text { In vivo (mice) }\end{array}$ & Curcumin up-regulates HLJ1 & $(54)$ \\
\hline
\end{tabular}

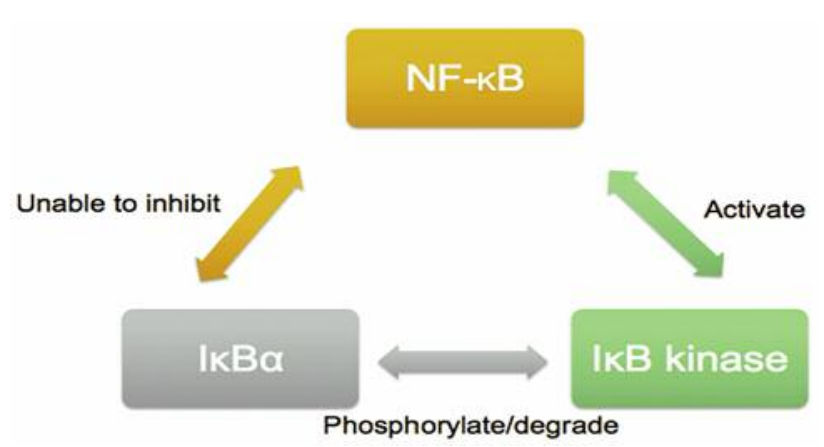

Figure 2. Constitutive activation of $N F-k B$ signaling pathway. The activation of $N F-K B$ (e.g., induced by viral infection) is initiated by degradation of $I_{k} B$ (inhibitor of $\kappa B$ ) proteins: $N F-k B$ activates $I k B$ kinase (IKK) enzymes that phosphorylate and degrade IkB $\alpha$. Phosphorylated I $\mathrm{kB \alpha}$ is unable to inhibit the activation of $N F-k B$, which leads to a constitutive activation of $N F-k B$.

Curcumin inhibits signal transducer and activator of transcription 3 (STAT3). STAT3 is constitutively activated in cancer cells and STAT3-regulated gene products are involved in cellular cycle, survival, angiogenesis and metastasis (18, 31). Particularly, it has been shown that the level of activated STAT 3 is associated with metastasis in different types of cancer tumors. Curcumin acts as a suppressor of interleukin6 (IL-6) cytokine signaling pathway and binds to the Janusactivated kinase (JAK) activation loop, thereby blocking

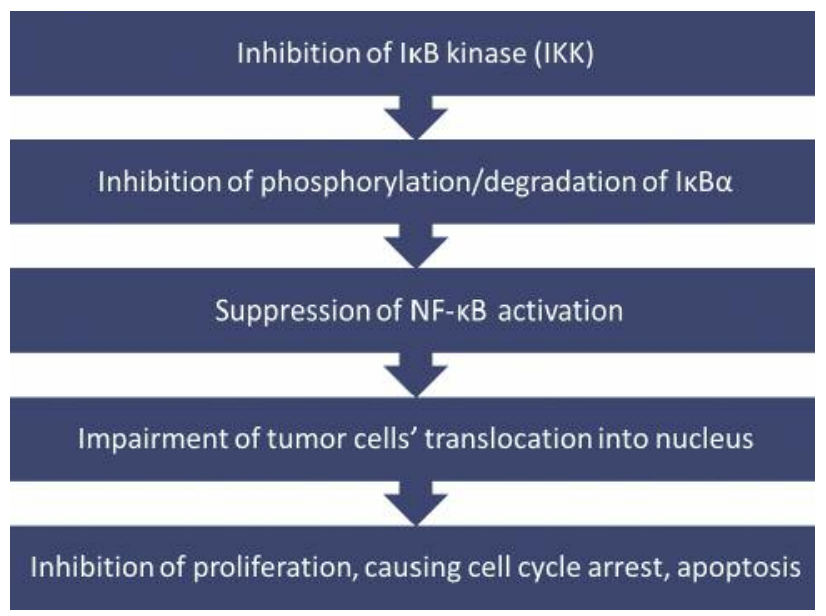

Figure 3. Curcumin suppresses $N F-\kappa B$ activation.

subsequent signaling that requires the phosphorylation and activation of STAT 3 (16). Yang et al. reported that curcumin inhibited IL-6-inducible STAT3 phosphorylation in a time- and dose-dependent manner in small-cell lung carcinoma (SCLC) cells (16). Their results also indicated that phosphorylation of STAT3 depended on the activation of JAKs, especially JAK2 , and curcumin inhibited JAK phosphorylation in SCLC cells. STAT3-regulated gene products, including vascular endothelial growth factor (VEGF) and MMP-2 and -9, were 
all down-regulated by curcumin. As STAT3 and its regulated gene products (VEGF, MMP-2 and -9) were significantly suppressed by curcumin, curcumin treatment reduced the metastasis rate in SCLC cells. Kunnumakkara et al. also demonstrated that curcumin inhibited IL-6-induced STAT3 phosphorylation in myeloma cells (24).

Curcumin down-regulates inflammatory cytokines' expression. Chronic inflammation is the key risk factor for cancer development and progression (32, 33). Inflammatory cytokines contribute to this process as they have the ability to attract mononuclear cells to cancer sites and provide growth factors to enhance cancer development. Inflammatory cytokines CXCL1 and CXCL2 are shown to promote angiogenesis in vivo, which is an important process for tumor cells' growth (34). It has been shown that CXCL1 is able to promote migration of breast cancer cells in vitro (35). Bachmeier et al. have identified CXCL1 and -2 expression as the major targets of anti-cancer activity of curcumin in a breast cancer cell line (25). Their research demonstrated that curcumin down-regulates mRNA expression and protein secretion of CXCL1 and -2 in a metastatic breast cancer cell line (MDA-MB-231). Helbig et al. showed that NF-kB directly induces the expression of chemokine receptor CXCR4 to promote breast cancer cell migration and metastasis (4). As curcumin inhibits the activation of $\mathrm{NF}-\mathrm{kB}$, curcumin can, thereby, reduce breast cancer metastasis through reducing NF-kB-mediated expression of two inflammatory cytokines, CXCL1 and -2 , and reducing expression of the chemotactic receptor CXCR4.

Killian et al. showed that CXCL1 and -2 share an almost identical proximal promoter region that contains a perfect NF$\mathrm{kB}$ binging site (26). This result shows activation of NF- $\mathrm{kB}$ increases the expression of CXCL1 and -2 . Their results demonstrated that curcumin down-regulates CXCL-1 and -2 by targeting NF-kB signaling pathway in metastatic prostate cancer cell line. The group has also conducted an in vivo study in an orthotopic mouse model of hematogenous metastasis. Their results indicated that curcumin treatment significantly inhibited the formation of prostate cancer lung metastasis. Metastasis of prostate cancer was induced by maintaining a positive pro-inflammatory and pre-metastatic feedback loop between NF-kB and CXCL1 and -2 signaling pathways. Curcumin interrupted this feedback loop by inhibiting NF-kB activation and down-regulating $\mathrm{CXCL} 1,-2$, which led to reduced metastasis of prostate cancer in the lungs.

Curcumin inhibits expression of interleukins (ILs). Interleukins are a group of cytokines that mediate and regulate acute inflammatory immune reactions. Freund et al. reported that IL-8 was overexpressed in ER-negative cancer cells but not in ER-positive cell line (36). Their results further concluded that IL-8 expression is negatively correlated to ER status and expressed preferentially in invasive cancer cells, which suggests a potential correlation between IL-8 expression and tumor progression and invasiveness. Another study also suggested that the overexpression of IL-8 associated with progression and metastasis of cancer cells in colon (37). Wang et al. found that neurotensin, a gut tridecapeptide that acts as a cellular mitogen in colorectal and pancreatic cancers, selectively stimulated $I L-8$ gene expression in human colon cancer cells; thus, cancer cell migration is increased when treated with IL-8 (30). As mentioned above their results showed that treatment of colon cancer cells using curcumin inhibited neurotensin-induced $I L-8$ gene expression and protein secretion in a dose-dependent manner, preventing migration of cancer cells (30). Curcumin also decreased IL-8 expression in human pancreatic cancer cell line (38).

Curcumin inhibits urokinase plasminogen activator (uPA) expression. uPA is a serine-specific protease that is released from tumor cells. It binds to uPA receptor (UPAR) to activate protease plasmin, which then degrades extracellular matrix (ECM) $(3,11)$. Extensive degradation of ECM of the primary tumor cells is a critical step for cancer invasion and subsequently metastasis. NF-kB is responsible for regulating uPA secretion. Zong et al. showed that curcumin significantly decreased the expression of uPA in a dose-dependent manner and NF-kB DNA binding activity in breast cancer cell line (MCF-7) (11). Based on their results, they suggested that curcumin inhibits the adhesion and invasion of breast cancer cells through down-regulating the expression of uPA via inhibiting NF-kB activation.

Curcumin suppresses the expression of matrix metalloproteinases (MMPs). MMPs are a group of zinc-containing endopeptidases capable of degrading extracellular matrix proteins and, thereby, play a major role in regulating ECM turnover and remodeling (3). By degrading the ECM and basement membrane, MMPs promote tumor migration of cancer cells from the original tumor and invade surrounding tissues and other organs by entering into blood stream and lymphatic system and travel to distant organ sites. During normal physiological conditions, the expression of MMPs is finely controlled and their activities are regulated by tissue inhibitors of metalloproteinases (TIMPs). However, when the balance between MMPs and TIMPs is disrupted, overexpression of MMPs will result in numerous pathogenic processes, including tumor invasion and metastasis $(39,40)$. Overexpression of MMPs observed in most of human cancer cells and high levels of MMPs are linked to metastasis (12). MMP-2 and -9 are the two main proteases that degrade the major component of basement membrane, type IV collagen, which, in turn, promote metastasis, especially in breast cancer $(13,14)$. Therefore, MMP-2 and -9 are the key therapeutic targets for anti-metastatic agents. 
12-O-tetradecanoylphorbol-13-acetate (TPA) is a tumor promoter and promotes invasion of breast cancer cells (MCF7) by inducing MMP-9 via protein kinase $\mathrm{C}$ (PKC) pathways $(14,41)$. In fact, TPA activates PKCs by binding to the $\mathrm{Cl}$ domain. Kim et al. demonstrated that curcumin inhibited TPA-induced MMP-9 expression and cell invasion via suppressing NF-kB and AP-1 activation. Curcumin also strongly inhibited the TPA-induced phosphorylation of $\mathrm{p} 38$ and JNK, as well as TPA-induced translocation of PKC $\alpha$ from the cytosol to the membrane (14).

In a study on curcumin's anti-invasive effects on ERnegative breast cancer cell line (MDA-MB-231), Shao et al. demonstrated that curcumin has a strong anti-invasive effect in a dose-dependent manner. It was suggested that curcumin down-regulates MMP-2 and up-regulates TIMP-1, -2 (42). TIMPs regulate tumor cell invasion by inhibiting MMP activity through non-covalent binding of the active zincbinding sites of MMPs (43). Additionally, Shao et al. showed that curcumin is a potent inhibitor of VEGF and basic fibroblast growth factor (b-FGF) in ER-negative breast cancer cells (42). Hassan et al. also showed that curcumin inhibited metastasis in an ER-negative cell line by down-regulating the expression of MMP-2 and -9 and up-regulating the expression of TIMP-1 and -4 in a time- and concentration-dependent manner (12). Based on their results, they suggested that curcumin significantly decreases MMP-9 functional ability by inhibiting its production, as well as up-regulating TIMP-1 and TIMP-4 gene expression in breast cancer cells.

Farhangi et al. used dendrosomal curcumin (DNC) to test curcumin's anti-metastatic properties on a metastatic breast cancer cell line (4T1) (44). Their results indicated that curcumin inhibited 4T1 cell viability, migration and adhesion in a time- and concentration-dependent manner, which, in turn, inhibited cell metastasis. DNC suppressed NF-kB, which led to down-regulation of MMP-9, VEGF and cyclooexgenase-2 (COX-2). An in vivo study was also conducted and stated that DNC was safe at $80 \mathrm{mg} / \mathrm{kg}$ in mice and treated mice had higher survival rate, lower metastatic rate and smaller tumor volume than control untreated group.

Overexpression of MMPs does not only occur in breast cancer but it has also been observed in other cancers, such as in the lungs. As observed in breast cancer cells, curcumin inhibited the migration and invasion of human lung cancer cells (A549) in a time- and concentration-dependent manner by inhibiting MMP-2 and -9 and VEGF (13). Chen et al. also reported curcumin's anti-invasion effects in vitro on human lung cancer cells (801D) and in vivo in a mouse model (45). The results showed that curcumin inhibits tumor cell migration and invasion both in vitro and in vivo partly due to its ability of inhibiting Rac-dependent signaling pathways and down-regulating the expression of MMP-2, -9. Expression of MMPs is induced by overexpression of Ras homolog gene family member A (RhoA), which then promotes the invasion of tumor cells (46). Sun et al. showed the lysophosphatidic acid (LPA) activated RhoA/MMPs signaling pathways increased in breast cancer cells (MCF-7), which enhanced invasion ability of cancer cells (46). They reported that bcurcumin was able to inhibit LPA-induced invasion in breast cancer cells by attenuating RhoA/ROCK (Rho-associated protein kinase)/MMPs pathway.

Wang et al. demonstrated that curcumin inhibited the expression of the tumor promoter caveolin-1 (Cav-1) in mouse hepatoma Hca-F cells (15). Curcumin downregulated the expression of cluster of differentiation (CD)147, MMP-2, -9 and inhibited the phosphorylation of epidermal growth factor receptor (EGFR) in Hca-F cells. They suggested that curcumin suppresses the migratory and invasive ability of Hca-F cells and this action is mediated through a mechanism involving inactivation of Cav-1 and EGFR signaling pathways.

Cheng et al. also suggested that curcumin inhibits the expression of MMP-2, -9 in prostate cancer cells (47). By comparing the expression of MMP-2 and -9 , they found curcumin has more inhibitory effect on MMP-9 compared to MMP-2. Additionally, they showed that the expression of serine protease (matriptase) was suppressed by curcumin, which, in turn, inhibited the matriptase-induced invasion in prostate cancer cells.

Curcumin inhibits focal adhesion kinase (FAK) activity. FAK is a protein kinase that is highly expressed in cancer cells, particularly breast and ovarian cancers, and involved in cellular adhesion regulating tumor cells' invasion and metastasis (48). Chen et al. reported an in vitro (colon cancer cell lines) and in vivo (mice) study to identify the effects of curcumin in terms of inhibiting metastasis (49). They suggested that curcumin inhibits migration and invasion in vitro and curcumin treatment significantly reduced primary tumor growth and number of liver metastatic nodules. They suggested that curcumin inhibited CD24, one of the major cell surface glycosylated proteins that function as an adhesive molecule of tumor cells. CD24 reduces FAK activity via inhibition of FAK phosphorylation. The study concluded that curcumin is a potential drug for the treatment of metastatic cancer because it inhibits cancer cell metastasis at different levels, particularly inhibition of transcription factors, cell adhesion molecules and cell surface markers, whereas it enhances cell adhesion ability and cell-cell tight junctions to prevent epithelial to mesenchymal transition (EMT). Leu et al. also reported the suppression of FAK activity by curcumin (50). Their results indicated that the activity of FAK was directly inhibited by curcumin in a colon cancer cell line. The reduction of Src kinase activity was medicated by curcumin, which then inhibited FAK phosphorylation and its activity, inhibiting colon cancer metastasis. 
Curcumin regulates microRNAS (miRNAs) expression. miRNAs are non-coding RNAs that regulate the translation and degradation of target messenger RNAs (mRNAs). Therefore, miRNAs regulate cellular proliferation, differentiation and apoptosis, closely associated with cancer (51-53). miRNAs regulate several proteins' expressions by binding to mRNA three prime untranslated region (3'UTR), which then degrades mRNA or inhibits mRNA translation (53). miRNAs have a dual effect in cancers, either acting as tumor promoters or tumor suppressors (53). miR-21 is upregulated in almost all cancers, including breast, lung, colon, liver and prostate $(51,52)$. miR21 promotes tumor cell proliferation, invasion and metastasis by targeting tumor suppressors, including programmed cell death protein 4 (PDCD4) and phosphatase and tensin homologue (PTEN) (51, 52). AP-1 controls the regulation of pri-miR-21 promoter and the results of Mudduluru et al. showed that curcumin inhibited the miR21 expression and activity in colorectal cancer cell lines by inhibiting AP-1 binding to pri-miR-21 promoter in a dose-dependent manner (51). Curcumin also induced the expression of PDCD4 in vitro. Migration and invasion assays showed that curcumin treatment of colorectal cancer cells significantly decreased cell migration and invasion. They also conducted an in vivo metastasis study where colorectal cancer cells were inoculated in the upper chorioallantoic membrane (CAM) of 10-day-old chicken embryos. The results demonstrated that curcumin significantly inhibited metastasis of colorectal cancer cells both in vitro and in vivo and the authors concluded that curcumin can inhibit tumor invasion and metastasis by inhibiting miR2 1 expression via AP-1 and stabilizing PDCD4 in colorectal cancer.

As mentioned earlier, pro-inflammatory cytokines CXCL1 and -2 are up-regulated in breast cancer cells and curcumin significantly down-regulates CXCL1 and -2. Kronski et al. found that miR181b-mediated CXCL1 and -2 expression through direct binding to 3'UTR that mediated curcuminrelated down-regulation of CXCL1 and -2 in breast cancer cells (MDA-MB-231) (53). They also suggested that miR181b induces apoptosis and inhibits the expression of MMPs in vitro, thus inhibiting invasion of cancer cells. Lastly, they showed overexpressing of miR181b inhibits metastasis of breast cancer cells in vivo (immunodeficient mice). They concluded that curcumin inhibits metastasis of breast cancer cells by up-regulating miR181b and downregulating CXCL-1 and -2 .

Curcumin regulates DnaJ-like heat shock protein 40 (HLJ1) expression. HLJ1 is a heat shock protein (HSP) associated with progress of cancers and regulating cancer cell invasion and metastasis (54). HLJ1 is able to inhibit lung cancer cell proliferation and invasion; high HLJ1 expression is associated with reduced cancer recurrence and long overall survival of patients with non-small cell lung cancer (NSCLC). Chen et al. showed that curcumin inhibited tumor cell invasion and metastasis in both in vitro (CL1-5 cell, a high invasive lung cancer cell line) and in vivo (mouse model) through upregulating HLJ1. The possible mechanisms suggested by their results were a) curcumin up-regulates HLJ1 though upregulating JunD (an AP-1 compound) in a time- and concentration-dependent manner; and b) activation of HLJ1 by curcumin stimulates up-regulation of E-cadherin (act as an invasion suppresser), which, in turn, inhibits lung cancer cell invasion and metastasis.

\section{Combination Therapies of Curcumin and Other Medications}

As mentioned above, there are many possible molecular mechanisms for anti-invasive and anti-metastatic activities of curcumin that have been reported in in vitro and in vivo studies. As curcumin affects cancer cells at different levels and through different signaling pathways, the possible combination or synergistic effects of curcumin and other anticancer drugs on metastatic cancers have been studies and are explored in this section.

Duarte et al. conducted in vitro and in vivo studies to identity the effects of using curcumin in combination with cisplatin in head and neck squamous cell carcinoma (HNSCC) treatment (55). They used two HNSCC cell lines and treated them with curcumin or cisplatin alone or in combination. In that work, the in vivo study consisted of intravenous tail vein injection of liposomal curcumin or with intraperitoneal cisplatin, into nude mice growing xenograft HNSCC tumors. Results demonstrated that the administration of curcumin and suboptimal concentrations of cisplatin showed a significant cancer suppressive effect. Additionally, the team showed curcumin inhibited NF-kB activation and cisplatin induced apoptosis though p53 pathway. Since curcumin and cisplatin destroy cancer cells via different pathways, this combination therapy potentially improves cancer treatment by synergistic anti-cancer effects of these agents, minimizing the adverse side-effects of cisplatin. LoTempio et al. had also previously suggested that curcumin suppresses the growth of HNSCC cell lines in vitro and reduces tumor volume in vivo via topical application (56).

Yin et al. conducted in vitro (A549 cells) and in vivo (A549 transplanted xenograft model) studies to identify possible effects of combining curcumin and docetaxel in lung cancer (57). Docetaxel is considered the first-line chemotherapy for lung cancer; however, it causes severe toxicity even at therapeutic doses and yields poor response rates as monotherapy. Results showed that curcumin synergistically increased the efficacy of docetaxel after 4 days of initial treatment; simultaneous administration of curcumin and docetaxel showed little toxicity to normal tissues, including bone marrow and liver at therapeutic doses. 
Shakibaei et al. used an alginate-based 3D scaffold to screen the possible anti-tumor-effects of combining curcumin and 5-fluorouracil (5-FU) on colorectal cancer cells (HCT116) (58). Overexpressed tumor promoting factors (e.g., CXCR4, MMP-9, NF-kB) in HCT116 cells promote proliferation, invasion and metastasis. Shakibaei et al. demonstrated that curcumin was able to further enhance the ability of 5-FU to decrease cancer cell proliferation and invasion. Curcumin increased the sensitivity of 5-FU through down-regulating NF-kB activation and NF-kB-regulated gene products. The combination therapy of curcumin and 5-FU was proposed as a potential treatment for colorectal cancer and may overcome the drug resistance in cancer cells.

Paclitaxel is a chemo-agent to treat breast cancer. However, because of paclitaxel-induced drug resistance through NF- $\mathrm{KB}$ activation, paclitaxel is not effective in treating advanced breast cancers (59). Aggarwal et al. have investigated curcumin therapy by using paclitaxel (Taxol)-resistant breast cancer cells and a human breast cancer xenograft animal model (60). Results showed that curcumin significantly inhibited paclitaxel-induced NF-kB activation and metastatic proteins in vitro and significantly decreased the incidence of breast cancer metastasis to the lungs through suppressing NF$\mathrm{kB}, \mathrm{COX}-2$ and MMP-9.

\section{Conclusion}

Curcumin is well-known for its anti-cancer activities in all different stages of cancer progress: transformation of normal cells to cancer cells; cancer cell proliferation; and tumor invasion. There are many research studies that have shown curcumin significantly inhibits metastasis in various types of cancers by regulating different signaling pathways. The potential anti-metastatic mechanisms of curcumin include inhibition of transcription factors and their signaling pathways (e.g., NF-kB, ApP-1 and STAT3), inflammatory cytokines (e.g., CXCL1, CXCL2, IL-6, IL-8), multiple proteases (e.g., uPA, MMPs), multiple protein kinases (e.g., MAPKs, FAK), regulation of miRNAs (e.g., miR21, miR181b) and heat shock proteins (HLJ1).

In addition to identify its potential therapeutic effects, the safety of curcumin and its appropriate therapeutic dose should also be determined. A phase I clinical trial conducted by Bayet-Robert et al. suggested that the recommended dose of curcumin is $6 \mathrm{~g}$ /day for seven consecutive days every three weeks in combination with a standard dose of docetaxel in patients with advanced and metastatic breast cancer (61). A phase I clinical study conducted by Cheng et al. in patients with high-risk or pre-malignant lesions concluded that curcumin is not toxic to humans up to $8 \mathrm{~g}$ /day when taken orally for 3 months (62). Dhillon et al. conducted a phase II trial in twenty-one advanced pancreatic cancer patients by giving $8 \mathrm{~g}$ oral dose of curcumin daily until disease progression (63). They reported two patients changed cytokine levels after curcumin treatment. One patient had ongoing stable disease for more than 18 months and slow improvement over 1.5 years. Another patient had a brief but marked tumor regression $(73 \%)$.

Curcumin has been used as a dietary spice for centuries and its potential in cancer therapy supported by numerous research studies. However, there are few studies indicating possible negative effects of curcumin in cancer treatment. An in vivo study conducted by Yan showed curcumin enhanced metastatic growth of Lewis lung carcinoma (LLC) in mice (64). Curcumin treatment significantly increased metastatic tumor cross-sectional area by $46 \%$ and volume by $70 \%$. Curcumin increased plasma concentration of angiogenin (angiogenic factor), VEGF, IL- $1 \beta$ and monocyte chemotactic protein-1 (MCP-1), which is believed to have contributed to the enhanced metastatic growth of LLC in mice. Yan et al. conducted another study to investigate the effects of curcumin on bone microstructure in non-tumor-bearing and LLCbearing mice (65). They reported the possibility of a combined effect of cancer-induced osteolysis and curcuminstimulated bone loss in patients treated with curcumin.

The future studies on anti-metastasis activities of curcumin should be directed towards efficacy and safety of curcumin in preventing cancer metastasis in animal models and clinical trials. There are still two major problems of using curcumin in cancer treatment/prevention that limit its clinical application. Curcumin has low bioavailability due to low water solubility, rapid metabolic rate and systemic clearance; it has also low chemical stability (10). Curcumin nanoparticles have shown potential to improve its anti-cancer activities through enhanced cellular uptake, localization to targeted areas and improved bioavailability. Liposomes, polymeric micelles and polymeric nanoparticles are the common nano-carries employed for encapsulation of curcumin (10). Further effort to modify curcumin nanoparticles for targeting cancer cells (e.g., coating nanoparticles with antibodies/peptides that bind to overexpressed receptors on the surface of cancer cells) should also be envisaged in future studies.

\section{References}

1 Bray F, Ren JS, Masuyer E and Ferlay J: Global estimates of cancer prevalence for 27 sites in the adult population in 2008. Int J Cancer 132: 1133-1145, 2013.

2 Coghlin C and Murray GI: Current and emerging concepts in tumour metastasis. J Pathol 222: 1-15, 2010.

3 Brooks SA, Lomax-Browne HJ, Carter TM, Kinch CE and Hall DMS: Molecular interactions in cancer cell metastasis. Acta Histochem 112: 3-25, 2010.

4 Helbig G, Christopherson KW, Bhat-Nakshatri P, Kumar S, Kishimoto H, Miller KD, Broxmeyer HE and Nakshatri H: NFkappa B promotes breast cancer cell migration and metastasis by inducing the expression of the chemokine receptor CXCR4. J Biol Chem 278: 21631-21638, 2003. 
5 Liotta LA: Cancer - An attractive force in metastasis. Nature 410 : 24-25, 2001

6 Gupta SC, Patchva S, Koh W and Aggarwal BB: Discovery of curcumin, a component of golden spice, and its miraculous biological activities. Clin Exp Pharmacol P 39: 283-299, 2012.

7 Lee WH, Bebawy M, Loo CY, Luk F, Mason RS and Rohanizadeh R: Fabrication of Curcumin Micellar Nanoparticles with Enhanced Anti-Cancer Activity. J Biomed Nanotechnol 11: 1093-1105, 2015.

8 Lee WH, Loo CY, Bebawy M, Luk F, Mason RS and Rohanizadeh R: Curcumin and its derivatives: their application in neuropharmacology and neuroscience in the 21 st century. Curr Neuropharmacol 11: 338-378, 2013.

9 Lee WH, Loo CY, Young PM, Rohanizadeh R and Traini D: Curcumin nanoparticles attenuate production of pro-inflammatory markers in lipopolysaccharide-induced macrophages. Pharm ResDordr 33: 315-327, 2016.

10 Lee WH, Loo CY, Young PM, Traini D, Mason RS and Rohanizadeh R: Recent advances in curcumin nanoformulation for cancer therapy. Expert Opin Drug Del 11: 1183-1201, 2014.

11 Zong H, Wang F, Fan QX and Wang LX: Curcumin inhibits metastatic progression of breast cancer cell through suppression of urokinase-type plasminogen activator by NF-kappa B signaling pathways. Mol Biol Rep 39: 4803-4808, 2012.

12 Hassan ZK and Daghestani MH: Curcumin Effect on MMPs and TIMPs Genes in a Breast Cancer Cell Line. Asian Pac J Cancer P 13: 3259-3264, 2012.

13 Lin SS, Lai KC, Hsu SC, Yang JS, Kuo CL, Lin JP, Ma YS, Wu $\mathrm{CC}$ and Chung JG: Curcumin inhibits the migration and invasion of human A549 lung cancer cells through the inhibition of matrix metalloproteinase-2 and-9 and Vascular Endothelial Growth Factor (VEGF). Cancer Lett 285: 127-133, 2009.

14 Kim JM, Noh EM, Kwon KB, Kim JS, You YO, Hwang JK, Hwang BM, Kim BS, Lee SH, Lee SJ, Jung SH, Youn HJ and Lee YR: Curcumin suppresses the TPA-induced invasion through inhibition of PKC alpha-dependent MMP-expression in MCF-7 human breast cancer cells. Phytomedicine 19: 1085-1092, 2012.

15 Wang SJ, Yu SJ, Shi W, Ge L, Yu X, Fan JH and Zhang JN: Curcumin Inhibits the Migration and Invasion of Mouse Hepatoma Hca-F Cells Through Down-regulating Caveolin-1 Expression and Epidermal Growth Factor Receptor Signaling. Iubmb Life 63: 775-782, 2011.

16 Yang CL, Liu YY, Ma YG, Xue YX, Liu DG, Ren Y, Liu XB, Li $\mathrm{Y}$ and $\mathrm{Li} \mathrm{Z}$ : Curcumin blocks small cell lung cancer cells migration, invasion, angiogenesis, cell cycle and neoplasia through Janus kinase-STAT3 signalling pathway. PLoS One 7(5): e37960, 2012.

17 Shishodia S: Molecular mechanisms of curcumin action: Gene expression. Biofactors 39: 37-55, 2013.

18 Fan YH, Mao RF and Yang JH: NF-kappa B and STAT3 signaling pathways collaboratively link inflammation to cancer. Protein Cell 4: 176-185, 2013.

19 Aggarwal BB: Nuclear factor-kappa-B: The enemy within. Cancer Cell 6: 203-208, 2004.

20 Jacobs MD and Harrison SC: Structure of an I kappa B alpha/NFkappa B complex. Cell 95: 749-758, 1998.

21 Verma IM, Stevenson JK, Schwarz EM, Vanantwerp D and Miyamoto S: Rel/Nf-Kappa-B/I-Kappa-B Family - Intimate Tales of Association and Dissociation. Gene Dev 9: 2723-2735, 1995.

22 Nelson DE, Ihekwaba AEC, Elliott M, Johnson JR, Gibney CA, Foreman BE, Nelson G, See V, Horton CA, Spiller DG, Edwards
SW, McDowell HP, Unitt JF, Sullivan E, Grimley R, Benson N, Broomhead D, Kell DB and White MRH: Oscillations in NFkappa B signaling control the dynamics of gene expression. Science 306: 704-708, 2004.

23 Baldwin AS: Control of oncogenesis and cancer therapy resistance by the transcription factor NF-kappa B. J Clin Invest 107: 241-246, 2001.

24 Kunnumakkara AB, Anand P and Aggarwal BB: Curcumin inhibits proliferation, invasion, angiogenesis and metastasis of different cancers through interaction with multiple cell signaling proteins. Cancer Lett 269: 199-225, 2008.

25 Bachmeier BE, Mohrenz IV, Mirisola V, Schleicher E, Romeo F, Hohneke C, Jochum M, Nerlich AG and Pfeffer U: Curcumin down-regulates the inflammatory cytokines CXCL1 and-2 in breast cancer cells via NF kappa B. Carcinogenesis 29: 779-789, 2008.

26 Killian PH, Kronski E, Michalik KM, Barbieri O, Astigiano S, Sommerhoff CP, Pfeffer U, Nerlich AG and Bachmeier BE: Curcumin inhibits prostate cancer metastasis in vivo by targeting the inflammatory cytokines CXCL1 and -2. Carcinogenesis 33: 2507-2519, 2012.

27 Singh S and Aggarwal BB: Activation of Transcription Factor NfKappa-B Is Suppressed by Curcumin (Diferulolylmethane). J Biol Chem 270: 24995-25000, 1995.

28 Angel P, Hattori K, Smeal T and Karin M: The Jun ProtoOncogene Is Positively Autoregulated by Its Product, Jun/Ap-1. Cell 55: 875-885, 1988.

29 Park J and Conteas CN: Anti-carcinogenic properties of curcumin on colorectal cancer. World journal of gastrointestinal oncology 2: 169-176, 2010.

30 Wang XF, Wang QD, Ives KL and Evers BM: Curcumin inhibits neurotensin-mediated interleukin- 8 production and migration of HCT116 human colon cancer cells. Clin Cancer Res 12: 5346$5355,2006$.

31 Huang SY: Regulation of Metastases by signal transducer and activator of transcription 3 signaling pathway: Clinical implications. Clin Cancer Res 13: 1362-1366, 2007.

32 Lu HT, Ouyang WM and Huang CS: Inflammation, a key event in cancer development. Mol Cancer Res 4: 221-233, 2006.

33 Rollins BJ: Inflammatory chemokines in cancer growth and progression. Eur J Cancer 42: 760-767, 2006.

34 Strieter RM, Polverini PJ, Kunkel SL, Arenberg DA, Burdick MD, Kasper J, Dzuiba J, Vandamme J, Walz A, Marriott D, Chan SY, Roczniak S and Shanafelt AB: The functional-role of the Elr Motif in Cxc chemokine-mediated angiogenesis. J Biol Chem 270: 27348-27357, 1995.

35 Youngs SJ, Ali SA, Taub DD and Rees RC: Chemokines induce migrational responses in human breast carcinoma cell lines. Int $\mathrm{J}$ Cancer 71: 257-266, 1997.

36 Freund A, Chauveau C, Brouillet JP, Lucas A, Lacroix M, Licznar A, Vignon F and Lazennec G: IL-8 expression and its possible relationship with estrogen-receptor-negative status of breast cancer cells. Oncogene 22: 256-265, 2003.

$37 \mathrm{Li} \mathrm{AH}$, Varney ML and Singh RK: Expression of interleukin 8 and its receptors in human colon carcinoma cells with different metastatic potentials. Clin Cancer Res 7: 3298-3304, 2001.

$38 \mathrm{Li} \mathrm{L}$, Braiteh FS and Kurzrock R: Liposome-encapsulated curcumin - In vitro and in vivo effects on proliferation, apoptosis, signaling, and angiogenesis. Cancer 104: 1322-1331, 2005.

39 Chirco R, Liu XW, Jung KK and Kim HRC: Novel functions of TIMPs in cell signaling. Cancer Metast Rev 25: 99-113, 2006. 
40 Mylona E, Magkou C, Giannopoulou I, Agrogiannis G, Markaki S, Keramopoulos A and Nakopoulou L: Expression of tissue inhibitor of matrix metalloproteinases (TIMP)-3 protein in invasive breast carcinoma: Relation to tumor phenotype and clinical outcome. Breast Cancer Res 8, 2006.

41 Lee SO, Jeong YJ, Kim M, Kim CH and Lee IS: Suppression of PMA-induced tumor cell invasion by capillarisin via the inhibition of NF-kappa B-dependent MMP-9 expression. Biochem Bioph Res Co 366: 1019-1024, 2008.

42 Shao ZM, Shen ZZ, Liu CH, Sartippour MR, Go VL, Heber D and Nguyen M: Curcumin exerts multiple suppressive effects on human breast carcinoma cells. Int J Cancer 98: 234-240, 2002.

43 GomisRuth FX, Maskos K, Betz M, Bergner A, Huber R, Suzuki K, Yoshida N, Nagase H, Brew K, Bourenkov GP, Bartunik H and Bode W: Mechanism of inhibition of the human matrix metalloproteinase stromelysin-1 by TIMP-1. Nature 389: 77-81, 1997.

44 Farhangi B, Alizadeh AM, Khodayari H, Khodayari S, Dehghan MJ, Khori V, Heidarzadeh A, Khaniki M, Sadeghiezadeh M and Najafi F: Protective effects of dendrosomal curcumin on an animal metastatic breast tumor. Eur J Pharmacol 758: 188-196, 2015.

45 Chen QY, Zheng Y, Jiao DM, Chend FY, Hu HZ, Wu YQ, Song $\mathrm{J}$, Yan J, Wu LJ and Lv GY: Curcumin inhibits lung cancer cell migration and invasion through Rac1-dependent signaling pathway. J Nutr Biochem 25: 177-185, 2014.

46 Sun K, Duan XY, Cai H, Liu XH, Yang Y, Li M, Zhang XY and Wang JS: Curcumin inhibits LPA-induced invasion by attenuating RhoA/ROCK/MMPs pathway in MCF7 breast cancer cells. Clin Exp Med 16: 37-47, 2016.

47 Cheng TS, Chen WC, Lin YY, Tsai CH, Liao CI, Shyu HY, Ko CJ, Tzeng SF, Huang CY, Yang PC, Hsiao PW and Lee MS: Curcumin-Targeting Pericellular Serine Protease Matriptase Role in Suppression of Prostate Cancer Cell Invasion, Tumor Growth, and Metastasis. Cancer Prev Res 6: 495-505, 2013.

48 Cox BD, Natarajan M, Stettner MR and Gladson CL: New concepts regarding focal promotion of cell migration adhesion kinase and proliferation. J Cell Biochem 99: 36-52, 2006.

49 Chen CC, Sureshbabul M, Chen HW, Lin YS, Lee JY, Hong QS, Yang YC and Yu SL: Curcumin Suppresses Metastasis via Sp-1, FAK Inhibition, and E-Cadherin Upregulation in Colorectal Cancer. Evid-Based Compl Alt 2013.

50 Leu TH, Su SL, Chuang YC and Maa MC: Direct inhibitory effect of curcumin on Src and focal adhesion kinase activity. Biochem Pharmacol 66: 2323-2331, 2003.

51 Mudduluru G, Gerge-William JN, Muppala S, Asangani IA, Kumarswamy R, Nelson LD and Allgayer H: Curcumin regulates miR-21 expression and inhibits invasion and metastasis in colorectal cancer. Bioscience Rep 31: 185-197, 2011.

52 Tili E, Michaille JJ and Croce CM: MicroRNAs play a central role in molecular dysfunctions linking inflammation with cancer. Immunol Rev 253: 167-184, 2013.

53 Kronski E, Fiori ME, Barbieri O, Astigiano S, Mirisola V, Killian PH, Bruno A, Pagani A, Rovera F, Pfeffer U, Sommerhoff CP, Noonan DM, Nerlich AG, Fontana L and Bachmeier BE: miR $181 \mathrm{~b}$ is induced by the chemopreventive polyphenol curcumin and inhibits breast cancer metastasis via downregulation of the inflammatory cytokines CXCL1 and-2. Mol Oncol 8: 581-595, 2014.
54 Chen HW, Lee JY, Huang JY, Wang CC, Chen WJ, Su SF, Huang CW, Ho CC, Chen JJW, Tsai MF, Yu SL and Yang PC: Curcumin inhibits lung cancer cell invasion and metastasis through the tumor suppressor HLJ1. Cancer Res 68: 7428-7438, 2008.

55 Duarte VM, Han E, Veena MS, Salvado A, Suh JD, Liang LJ, Faull KF, Srivatsan ES and Wang MB: Curcumin enhances the effect of cisplatin in suppression of head and neck squamous cell carcinoma via inhibition of IKK beta protein of the NF kappa B pathway. Mol Cancer Ther 9: 2665-2675, 2010.

56 LoTempio MM, Veena MS, Steele HL, Ramamurthy B, Ramalingam TS, Cohen AN, Chakrabarti R, Srivatsan ES and Wang MB: Curcumin suppresses growth of head and neck squamous cell carcinoma. Clin Cancer Res 11: 6994-7002, 2005.

57 Yin HT, Guo R, Xu Y, Zheng YL, Hou ZB, Dai XZ, Zhang ZD, Zheng $\mathrm{DH}$ and $\mathrm{Xu} \mathrm{H}$ : Synergistic antitumor efficiency of docetaxel and curcumin against lung cancer. Acta Bioch Bioph Sin 44: 147-153, 2012.

58 Shakibaei M, Kraehe P, Popper B, Shayan P, Goel A and Buhrmann C: Curcumin potentiates antitumor activity of 5fluorouracil in a 3D alginate tumor microenvironment of colorectal cancer. Bmc Cancer 15, 2015.

59 Pianetti S, Arsura M, Romieu-Mourez R, Coffey RJ and Sonenshein GE: Her-2/neu overexpression induces NF-kappa B via a PI3-kinase/Akt pathway involving calpain-mediated degradation of I kappa-B-alpha that can be inhibited by the tumor suppressor PTEN. Oncogene 20: 1287-1299, 2001.

60 Aggarwal BB, Shishodia S, Takada Y, Banerjee S, Newman RA, Bueso-Ramos CE and Price JE: Curcumin suppresses the paclitaxel-induced nuclear factor-kappa B pathway in breast cancer cells and inhibits lung metastasis of human breast cancer in nude mice. Clin Cancer Res 11: 7490-7498, 2005.

61 Bayet-Robert M, Kwiatkowski F, Leheurteur M, Gachon F, Planchat E, Abrial C, Mouret-Reynier MA, Durando X, Barthomeuf $\mathrm{C}$ and Chollet P: Phase I dose escalation trial of docetaxel plus curcumin in patients with advanced and metastatic breast cancer. Cancer Biol Ther 9: 8-14, 2010.

62 Cheng AL, Hsu CH, Lin JK, Hsu MM, Ho YF, Shen TS, Ko JY, Lin JT, Lin BR, Wu MS, Yu HS, Jee SH, Chen GS, Chen TM, Chen CA, Lai MK, Pu YS, Pan MH, Wang YJ, Tsai CC and Hsieh CY: Phase I clinical trial of curcumin, a chemopreventive agent, in patients with high-risk or pre-malignant lesions. Anticancer Res 21: 2895-2900, 2001.

63 Dhillon N, Aggarwal BB, Newman RA, Wolf RA, Kunnumakkara AB, Abbruzzese JL, Ng CS, Badmaev V and Kurzrock R: Phase II trial of curcumin in patients with advanced pancreatic cancer. Clin Cancer Res 14: 4491-4499, 2008.

64 Yan L: Dietary supplementation with curcumin enhances metastatic growth of Lewis lung carcinoma in mice. Int J Cancer 132: 269-275, 2013.

65 Yan L, Yee JA and Cao J: Curcumin Reduces Trabecular and Cortical Bone in Naive and Lewis Lung Carcinoma-bearing Mice. Anticancer Res 33: 3153-3161, 2013.

Received August 12, 2016

Revised August 31, 2016

Accepted September 1, 2016 